\title{
Liquid separation in Cu-Zr-Ag ternary alloys
}

\author{
D. Janovszky ${ }^{1 \mathrm{a}}$, K. Tomolya ${ }^{1}$, A. Sycheva ${ }^{1}$, P.Pekker $^{1}$ A. Roósz ${ }^{1}$
}

\author{
${ }^{1}$ Hungarian Academy of Sciences-University of Miskolc, Materials Science Research Group, \\ Miskolc-Egyetemvaros H-3515, Hungary \\ ${ }^{\text {a}}$ Corresponding author: fekjd@uni-miskolc.hu
}

\begin{abstract}
While cooling beyond a certain temperature limit $\left(\mathrm{T}_{\mathrm{SEP}}\right)$ the $\mathrm{Cu}-\mathrm{Zr}-\mathrm{Ag}$ ternary melt of the separated field in the ternary diagram decomposes into an $\mathrm{Ag}$-rich liquid $\left(\mathrm{L}_{1}\right)$ and another liquid rich in $\mathrm{Cu}$ and $\mathrm{Zr}\left(\mathrm{L}_{2}\right)$ both under equilibrium and non-equilibrium conditions. The master alloy samples were melted and cast in a wedge-shaped copper mould, in order to obtain a gradient of cooling rate. The shape of separated melt, its size and distribution were investigated. The boundaries of the liquid ternary miscibility gap have been enlarged owing to high cooling rate. The results confirm that the volume fraction of the separated phases has increased due to higher cooling rate. Three microstructure types can be distinguished during the liquid separation process as a function of $\mathrm{L}_{1}$.
\end{abstract}

Keywords: Ag-Cu-Zr alloy, Liquid separation, Miscibility gap, Monotectic, Rapid solidification

\section{Introduction}

Under conventional solidification conditions, when a monotectic alloy is undercooled into the miscibility gap, the liquid-liquid phase separation takes place and two liquids form. Drops of the new liquid begin generally with the nucleation of the liquid minority phase in regular shape [1]. In immiscible alloys a composite microstructure in situ has formed with the crystalline spheres embedded in the matrix. In the past few years, various research papers have been published regarding the metastable liquid-liquid phase separation when the liquid separation can be achieved only by undercooling the liquid. This phenomenon is the case for some Cu-based alloy [2-3]. Amorphous/amorphous or amorphous/crystalline composites can be obtained owing to liquid separation depending on the glass forming ability of the immiscible liquids [4-5].

Bulk metallic glasses (BMGs) are generally mechanically brittle because of the absence of dislocations. In this type of materials, shear deformation is localized along narrow bands, characterized by a lower viscosity with respect to the bulk, leading to catastrophic fracture under tension [6]. The brittleness of the amorphous structure disappears owing to the alloying elements with positive heat of mixing if one of the separated liquids solidifies into the ductile crystalline phase. The amorphizable alloy transforms generally into monotectic alloy due to the addition of such an element. The liquid separation provides an opportunity to produce in situ a composite microstructure, where either the matrix or the separated drop has amorphous structure [7-8].

Kündig et al. opined that a metastable liquid phase miscibility gap exists in the $\mathrm{Cu}-\mathrm{Zr}$ - $\mathrm{Ag}$ ternary system [9]. Kang and Jung found based on their calculations that a stable ternary liquid miscibility gap did exist [10]. A liquid miscibility gap was observed in two master alloy ingots and rapidly quenched ribbons by A. Castellero et al. [11].

This research is based on the previous paper of ours [12] that focused on the stable miscibility gap border. In this work influence of the cooling rate on the microstructure and on the miscibility gap border location in the $\mathrm{Cu}-\mathrm{Zr}$ $\mathrm{Ag}$ alloy were studied considering wedge-shaped samples. The $\mathrm{Cu}_{40} \mathrm{Zr}_{20} \mathrm{Ag}_{40}, \mathrm{Cu}_{15} \mathrm{Zr}_{15} \mathrm{Ag}_{70}, \mathrm{Cu}_{30} \mathrm{Zr}_{10} \mathrm{Ag}_{60}$ alloys were chosen from the three main regions taking into account the amount of separated $\mathrm{Ag}$-rich liquid.

\section{Experiments}

The master alloy ingots were prepared by arc melting from a mixture of pure metals under purified argon atmosphere (min. $99.99 \mathrm{~m} \%$ ) with a Ti-getter. The compositions are given in Table 1 . The ingots were re-melted at least four times in a glassy carbon crucible by induction melting, followed by centrifugal casting into wedge-shaped copper moulds under argon atmosphere. Before melting the chamber was evacuated and purged with high-purity Ar. Wedge-shaped samples were selected in order to analyze the influence of the cooling rate $(30 \mathrm{~mm}$ high, $3 \mathrm{~mm}$ thick, $20 \mathrm{~mm}$ wide). According to our previous research [13], the cooling rate was above $20000 \mathrm{~K} / \mathrm{s}$ near the tip of the wedge sample. At its base the cooling rate was about $2000 \mathrm{~K} / \mathrm{sec}$. The samples were examined by scanning electron microscopy (SEM), using a Zeiss EVO MA and LS Series with an Energy Dispersive Spectroscopy EDAX DX4 (EDS). Backscattered electron images were obtained in order to get information about the composition of the phases. Additionally, we used transmission electron microscopy to confirm the existence of amorphous phase. The instrument applied was a FEI Tecnai G2 transmission electron microscope equipped with a $\mathrm{LaB}_{6}$ cathode. The acceleration voltage was $200 \mathrm{kV}$. The TEM sample was thinned by ion polishing method (Gatan PIPS). The thermal analysis was performed by a Netzsch 204 differential scanning calorimeter (DSC) under Ar atmosphere. Image analysis was performed by Quantimet equipment using Leica software, followed by an adequate sample preparation. In the 
black-and-white photographs, the light phases were detected by an image analyzer, which corresponded to the Ag-rich phase. The volume fraction of the areas rich in $\mathrm{Ag}$ or $\mathrm{Cu}-\mathrm{Zr}$ was determined by measuring the respective area fraction. The droplets with less than $0.5 \mu \mathrm{m}^{2}$ were disregarded due to the detection error.

\section{Results}

\begin{tabular}{|c|c|c|}
\hline \multirow{2}{*}{$\begin{array}{c}\text { Nominal compositions, } \\
\text { at Pet }\end{array}$} & \multicolumn{2}{|c|}{ Liquid separation } \\
\hline & in master alloy & in wedge-shape sample \\
\hline $\mathrm{Cu}_{40} \mathrm{Zr}_{20} \mathrm{Ag}_{40}$ & + & + \\
\hline $\mathrm{Cu}_{34} \mathrm{Zr}_{19} \mathrm{Ag}_{47}$ & + & + \\
\hline $\mathrm{Cu}_{30} \mathrm{Zr}_{20} \mathrm{Ag}_{50}$ & + & + \\
\hline $\mathrm{Cu}_{20} \mathrm{Zr}_{20} \mathrm{Ag}_{60}$ & + & + \\
\hline $\mathrm{Cu}_{37.5} \mathrm{Zr}_{14} \mathrm{Ag}_{48.5}$ & + & + \\
\hline $\mathrm{Cu}_{15} \mathrm{Zr}_{15} \mathrm{Ag}_{70}$ & + & + \\
\hline $\mathrm{Cu}_{20} \mathrm{Zr}_{10} \mathrm{Ag}_{70}$ & + & + \\
\hline $\mathrm{Cu}_{30} \mathrm{Zr}_{10} \mathrm{Ag}_{60}$ & + & + \\
\hline $\mathrm{Cu}_{30} \mathrm{Zr}_{30} \mathrm{Ag}_{40}$ & - & + \\
\hline $\mathrm{Cu}_{40} \mathrm{Zr}_{10} \mathrm{Ag}_{50}$ & - & + \\
\hline $\mathrm{Cu}_{45} \mathrm{Zr}_{20} \mathrm{Ag}_{35}$ & - & + \\
\hline $\mathrm{Cu}_{25} \mathrm{Zr}_{25} \mathrm{Ag}_{50}$ & - & + \\
\hline $\mathrm{Cu}_{36} \mathrm{Zr}_{42} \mathrm{Ag}_{22}$ & - & - \\
\hline $\mathrm{Cu}_{44} \mathrm{Zr}_{25} \mathrm{Ag}_{31}$ & - & - \\
\hline $\mathrm{Cu}_{50} \mathrm{Zr}_{25} \mathrm{Ag}_{25}$ & - & - \\
\hline $\mathrm{Cu}_{53} \mathrm{Zr}_{17} \mathrm{Ag}_{30}$ & - & - \\
\hline $\mathrm{Cu}_{42} \mathrm{Zr}_{40} \mathrm{Ag}_{18}$ & - & - \\
\hline $\mathrm{Cu}_{39.2} \mathrm{Zr}_{39.8} \mathrm{Ag}_{21}$ & - & - \\
\hline $\mathrm{Cu}_{30} \mathrm{Zr}_{40} \mathrm{Ag}_{30}$ & - & - \\
\hline $\mathrm{Cu}_{30} \mathrm{Zr}_{35} \mathrm{Ag}_{35}$ & - & - \\
\hline $\mathrm{Cu}_{10} \mathrm{Zr}_{20} \mathrm{Ag}_{70}$ & - & - \\
\hline $\mathrm{Cu}_{15} \mathrm{Zr}_{25} \mathrm{Ag}_{60}$ & - & - \\
\hline $\mathrm{Cu}_{50} \mathrm{Ag}_{50}$ & - & - \\
\hline $\mathrm{Cu}_{50} \mathrm{Zr}_{10} \mathrm{Ag}_{40}$ & - & - \\
\hline $\mathrm{Cu}_{32.5} \mathrm{Zr}_{32.5} \mathrm{Ag}_{35}$ & - & - \\
\hline
\end{tabular}

Master alloys (Table 1) were prepared in the field of metastable and stable liquid-liquid phase separation predicted and published by Kündig and Kang respectively [9-10]. After solidification, the examination of the microstructure showed that the liquid miscibility gap existed in 8 master alloys and additionally in 4 wedgeshaped samples which did not demonstrate liquid separation in master alloys (Fig. 1). It can be stated that these four compositions are located at the border of liquid miscibility gap. It was confirmed that cooling the melt beyond a certain limit $\left(\mathrm{T}_{\mathrm{SEP}}\right)$ resulted in a liquid phase separation into two liquids: one liquid was found rich in $\mathrm{Ag}$ (hereinafter referred to as $\mathrm{L}_{1}$ ), and the other one was found rich in $\mathrm{Cu}-\mathrm{Zr}$ (hereinafter referred to as $\mathrm{L}_{2}$ ). 


\section{- miscibility gap in master alloy and wedge}

a miscibility gap only in wedge Ag $t$ no liquid separation

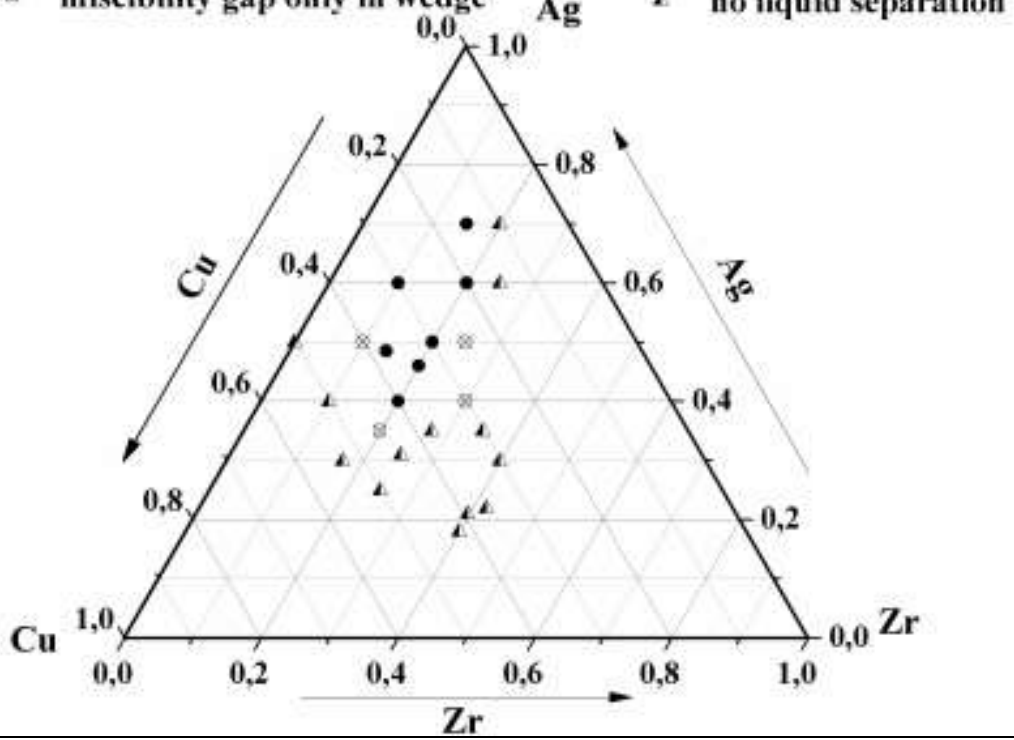

Fig. 1: Examined compositions in the $\mathrm{Cu}-\mathrm{Zr}-\mathrm{Ag}$ system

The following three different micro-structures were identified as function of the volume fraction of phase $\mathrm{L}_{1}$ in the 12 samples showing liquid miscibility:

- $\quad$ Region I, where liquid $\mathrm{L}_{1}$ occupies less than 50 Volume \%, is described by $\mathrm{Cu}_{40} \mathrm{Zr}_{20} \mathrm{Ag}_{40}$ composition. In these samples droplets of the $\mathrm{L}_{1}$ (Ag-rich) liquid are found dispersed in the matrix of the $\mathrm{Cu}-\mathrm{Zr}$-rich $\mathrm{L}_{2}$ liquid.

- In region II liquid $\mathrm{L}_{1}$ occupies about 50 Volume \%. A network of fine interconnected phases is detected here. The composition $\mathrm{Cu}_{15} \mathrm{Zr}_{15} \mathrm{Ag}_{70}$ represents this region.

- In region III liquid $\mathrm{L}_{1}$ occupies more than 50 Volume \%. In these samples droplets of the $\mathrm{L}_{2}(\mathrm{Cu}-\mathrm{Zr}$-rich) liquid are found dispersed in the matrix of the $\mathrm{Ag}$-rich $\mathrm{L}_{1}$ liquid. The $\mathrm{Cu}_{30} \mathrm{Zr}_{10} \mathrm{Ag}_{60}$ composition features this region.

The effect of cooling rate on the particle size has been studied by measuring areas of the separate droplets by image analysis of SEM images obtained in backscattered electrons. The distribution of the total area occupied by a specific class of particles was investigated at five different locations along the major axis of the wedge. The experimental data on the above mentioned three characteristic regions are presented in Fig. 2. The measured particle sizes have been related to the local cooling rate and superimposed in these diagrams. The estimation of the cooling rate (right axis) was carried out according to [13]. 


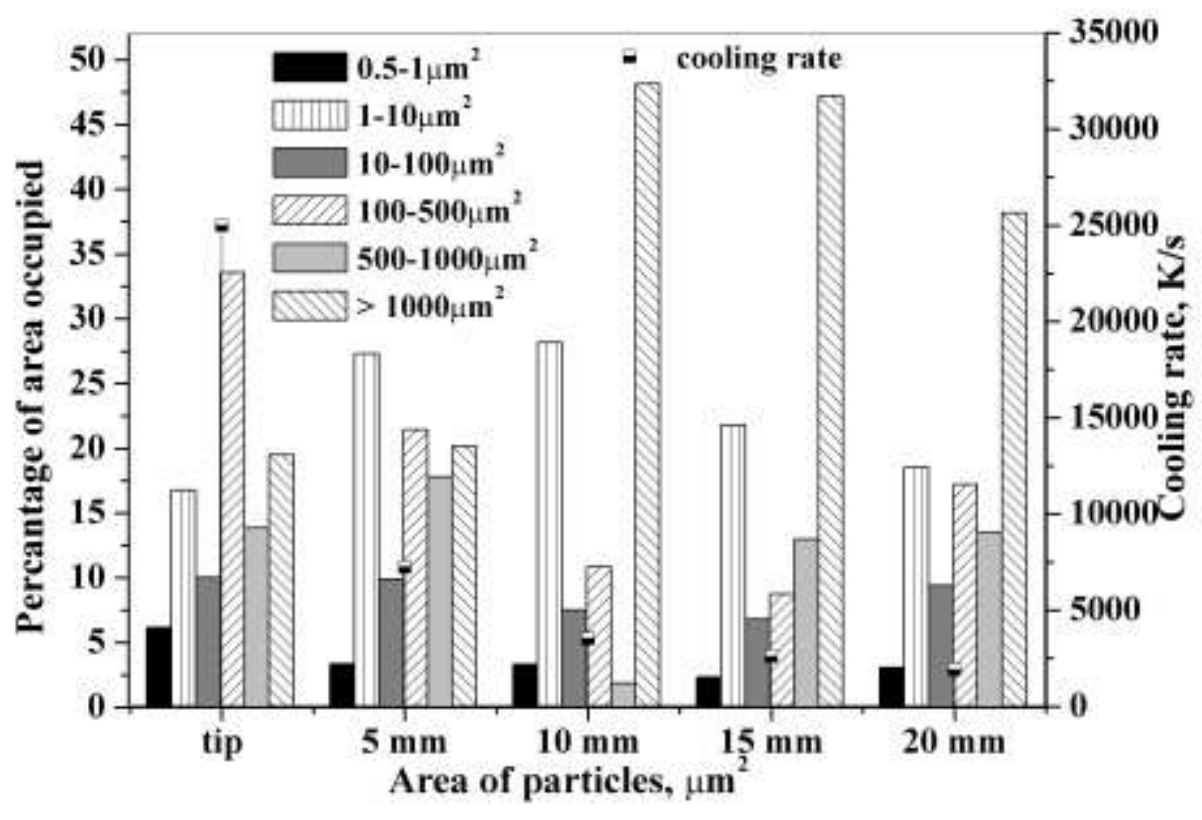

Fig. 2: Particle-size distribution of Ag-rich particles measured in different positions along the major axis of the wedge in the $\mathrm{Cu}_{40} \mathrm{Zr}_{20} \mathrm{Ag}_{40}$ sample. The estimation of the cooling rate (right axis) was carried out according to [13].

In Fig. 2 the difference in the $\mathrm{L}_{1}$ particle size and shape within one position and in different places in the sample with $\mathrm{Cu}_{40} \mathrm{Zr}_{20} \mathrm{Ag}_{40}$ (Region I) composition can be clearly seen. A gradient of cooling rate exists between the tip and the top of the wedge. The droplet size is relatively small at the tip; most of the particles are between 100 and $500 \mu \mathrm{m}^{2}$. The microstructure at two different positions can be seen in Fig. 3 .

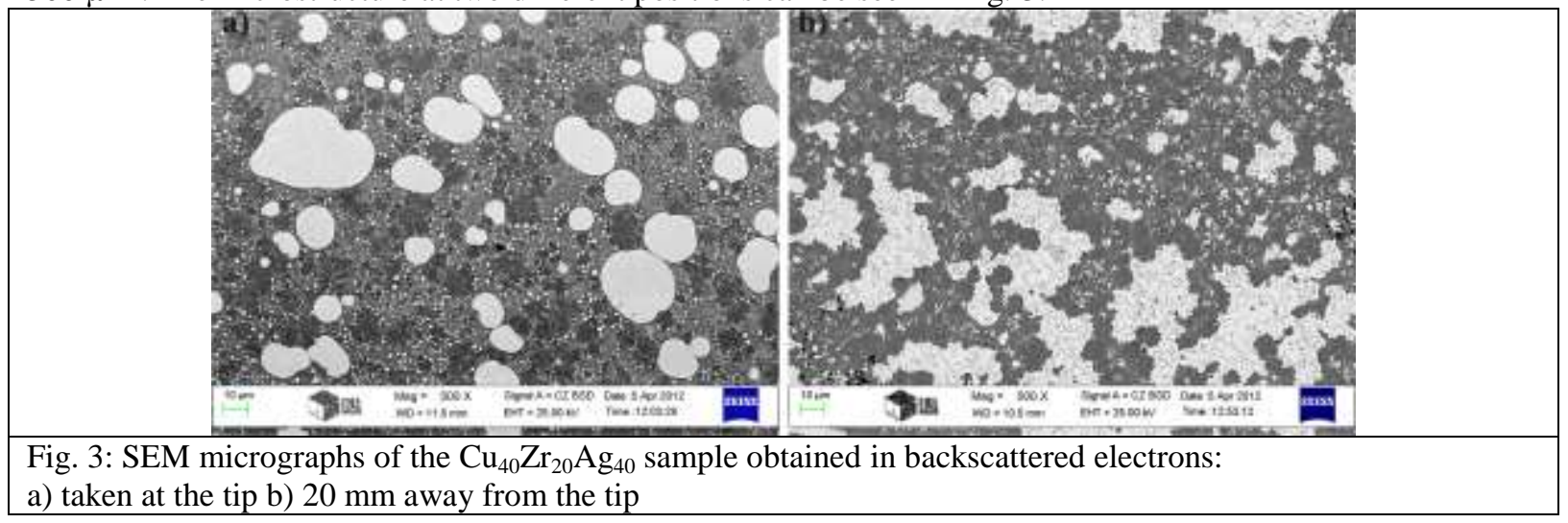

The bright regions are Ag-rich phases and the dark regions are $\mathrm{Cu}$-Zr-rich phases. It can be observed that there are a lot of droplets below $1 \mu \mathrm{m}^{2}$. A well-defined droplet-like structure developed from $\mathrm{L}_{1}$, and a number of droplet coagulations can be pointed out that reduce the interfacial energy between $\mathrm{L}_{1}$ and the other liquid phase. The Ag-rich droplets have about 82 at $\% \mathrm{Ag}$ content, $12-14$ at $\% \mathrm{Cu}$ content and very little $\mathrm{Zr}$ content. This composition is very similar to the composition of Ag-rich droplets in master alloy originating from stable liquid separation. The drops are covered by a thin layer with higher Ag concentration. Beyond $5 \mathrm{~mm}$ from the tip until the top the Ag-rich particles have no external layer and become irregular. The size of the separated melt is influenced by several factors: the Stokes effect, the Marangoni convection, temperature and concentration gradient, cooling rate and closely related undercooling, viscosity and diffusion [14]. Coagulation of smaller size (between 10 and $500 \mu \mathrm{m}^{2}$ ) droplets at the middle part of the wedge can be observed. The reason for that is the different heat conductivity of the phases. The Ag-rich droplets have higher heat conductivity as compared to the matrix. So the phases can transfer to a different extent the exothermic heat produced during liquid separation. That is why Ag-rich droplets can move to the middle part of the wedge and coagulate. At the same time, droplets above $5000 \mu \mathrm{m}^{2}$ decrease at the top of the sample, so the difference in size reduces. The size of Ag-rich phases increases with the distance from the tip of the wedge as the cooling rate decreases. In this wedge-shaped sample 
liquid $\mathrm{L}_{1}$ occupies about $32 \pm 4$ Volume \% with homogeneous distribution. On the contrary, in the master alloy wherefrom the wedge was cast, liquid $\mathrm{L}_{1}$ occupied only 17 Volume $\%$. We can conclude that beside the stable liquid separation a metastable liquid separation came off in the wedge. The EDS measurement showed that there was no compositional difference along the wedge.
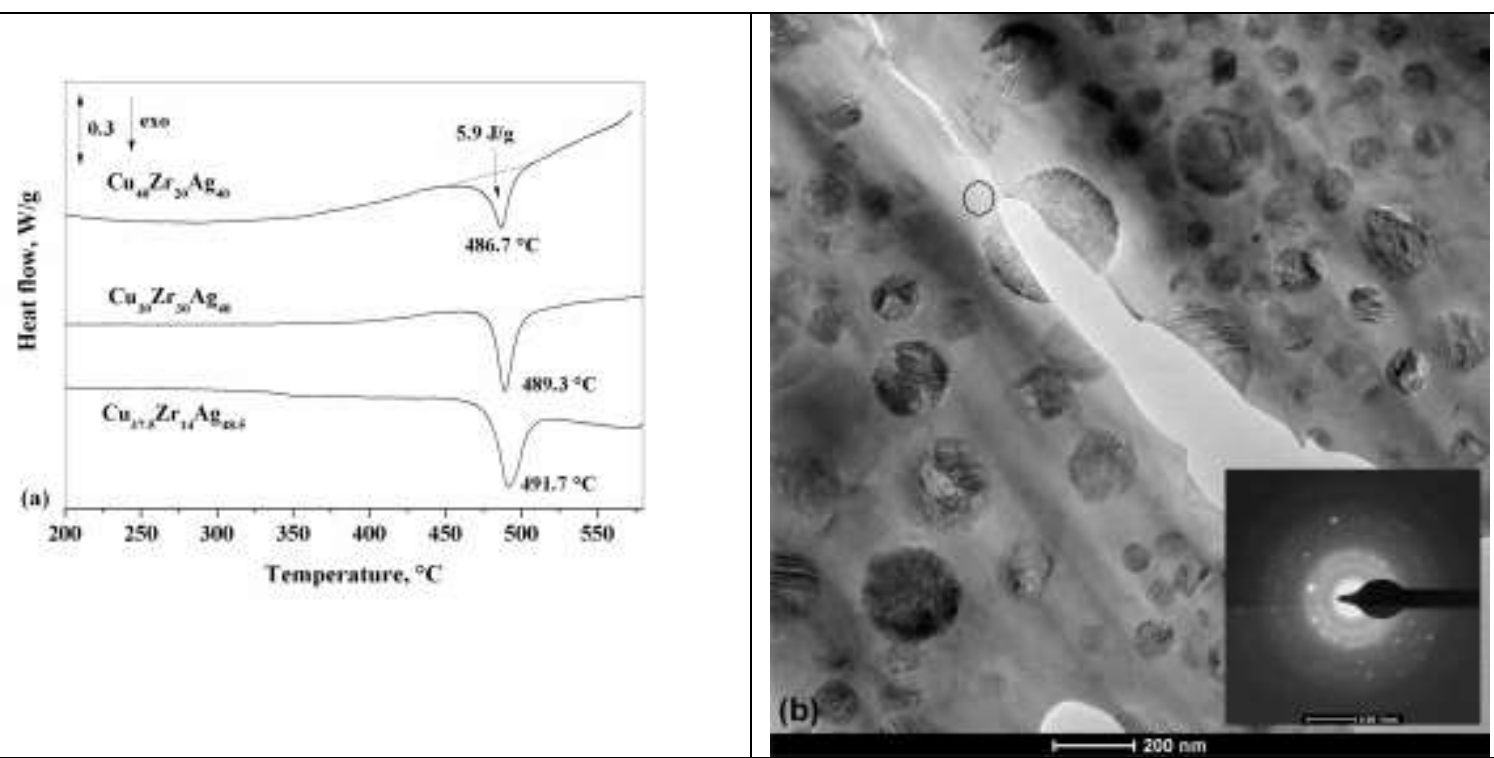

Fig. 4: DSC traces of the samples taken from the tip of the wedge with different compositions at a heating rate of $40{ }^{\circ} \mathrm{C} / \mathrm{min}$ (a), TEM image of $\mathrm{Cu}_{30} \mathrm{Zr}_{30} \mathrm{Ag}_{40}$ sample taken at the tip (b) and selected area diffraction pattern (SADP ). The place of the diffraction pattern (the circle) is marked on the image.

The DSC traces of the samples taken from the tip of the wedge are shown in Fig. 4a. The exothermic signals in the DSC traces manifest that these samples have amorphous part owing to liquid separation. In this case, the amorphous structure forms from the Ag-poor liquid. By the transmission electron microscope investigations nearly roundish, twinned silver crystals (with stacking faults) can be observed in amorphous-nanocrystalline matrix (Fig.4b.). The silver particles have the size of few tens or at most few hundreds of nanometers. The electron diffraction pattern made on an area of the matrix with $50 \mathrm{~nm}$ diameter shows diffuse rings and discrete reflections (Fig.4b insert.), which proves the presence of amorphous and also nanocrystalline parts in the matrix.

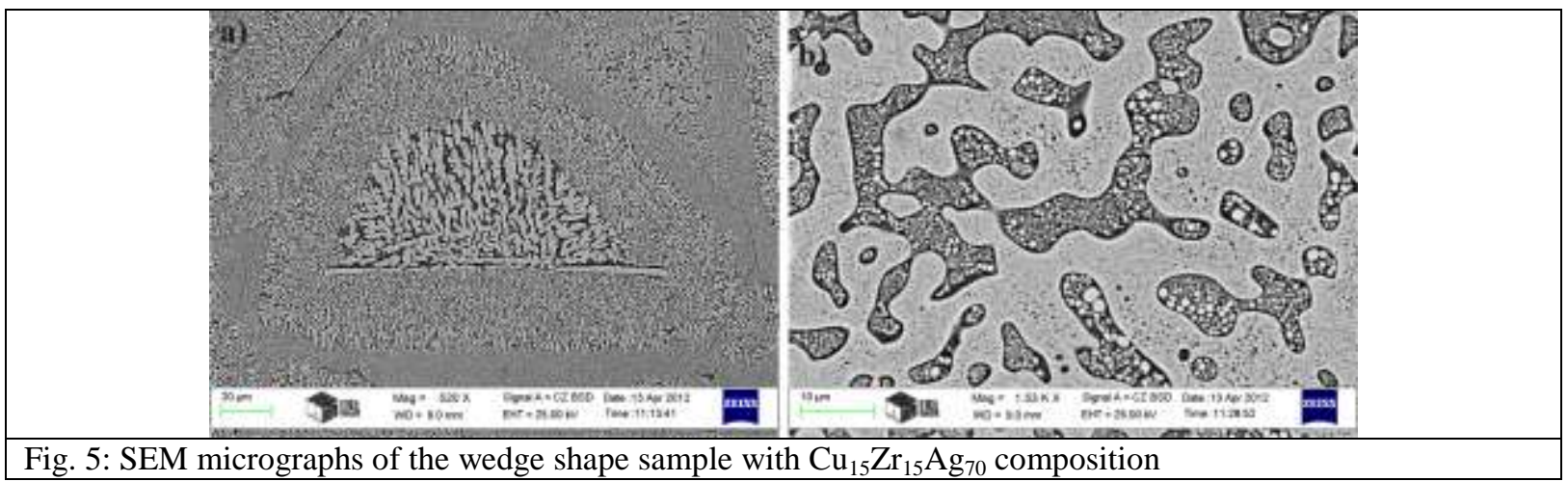

In wedge-shaped sample with $\mathrm{Cu}_{15} \mathrm{Zr}_{15} \mathrm{Ag}_{70}$ (Region II) composition the effect of melt flow can be better observed (Fig. 5a,b) and a peculiar microstructure can be seen. Both in the Ag-rich and in the $\mathrm{Cu}-\mathrm{Zr}$-rich large phases there are frozen small (internal) droplets, which separated from them during cooling (Fig. 5b). In the $\mathrm{Cu}-\mathrm{Zr}$ rich phases the volume fraction of Ag-rich internal droplets is 50-60 Volume \% and the average size is $630 \mathrm{~nm}$, the standard deviation is $350 \mathrm{~nm}$. In the Ag-rich phases the size of $\mathrm{Cu}$ - $\mathrm{Zr}$-rich internal droplets is generally below $200 \mathrm{~nm}$. In the master alloy this phenomenon is not observed.

The $\mathrm{Cu}-\mathrm{Zr}$-rich particle size distribution along the major axis of the wedge in the sample with $\mathrm{Cu}_{30} \mathrm{Zr}_{10} \mathrm{Ag}_{60}$ composition (Region III) is shown in Fig. 6. 


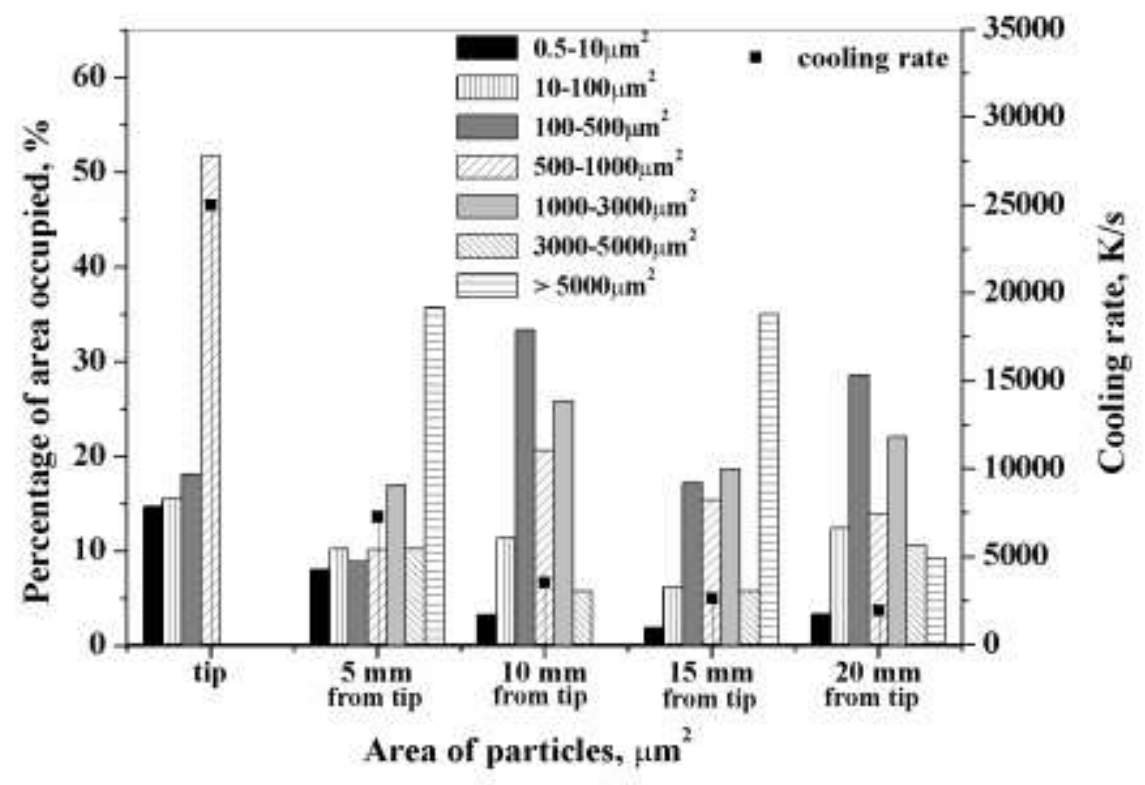

Fig. 6: Particle size distribution of Ag-rich particles measured in different positions along the major axis of the wedge in the $\mathrm{Cu}_{30} \mathrm{Zr}_{10} \mathrm{Ag}_{60}$ sample. The estimation of the cooling rate (right axis) was carried out according to [13].

The coagulation of $\mathrm{L}_{2}$ droplets at the tip is more significant compared to that of $\mathrm{L}_{1}$ droplets in Region $\mathrm{I}$. Here the droplets are also covered by a thin layer (Fig. 7). From the thermal conductivity point of view the situation is the opposite of Region I. The matrix has the highest heat conductivity; therefore the separated $\mathrm{L}_{2}$ droplets might be at slightly higher temperature than the matrix. The coagulation of $\mathrm{L}_{2}$ droplets takes place. The particles above $5000 \mu \mathrm{m}^{2}$ can be observed in the middle of the wedge. Additionally, some Ag-rich droplets are frozen within the large sphere rich in $\mathrm{Cu}$ and $\mathrm{Zr}$. These Ag-rich droplets which separated during cooling in large $\mathrm{Cu}-\mathrm{Zr}$-rich particle were too far from the boundary and the diffusion was too slow in order to pass out to the border. The $\mathrm{L}_{2}$ droplets become smaller and less spherical moving towards the top. At the top of the wedge the cooling rate is small so the coagulation should have taken place. Since the undercooling is also small, the separated volume fraction remains low. Measurement of volume fraction of the areas rich in $\mathrm{Cu}-\mathrm{Zr}$ confirms this assumption: the volume fraction of the separated $\mathrm{Cu}-\mathrm{Zr}$-rich phase is 45 Volume \%, 32 Volume \%, 41 Volume $\%$ and 35 Volume $\%$ at 5, 10, 15 and $20 \mathrm{~mm}$ from the tip, respectively. In the master alloy the liquid $\mathrm{L}_{2}$ occupies 14.7 Volume \%. There is no compositional difference in the wedge based on the EDS measurements. The $\mathrm{L}_{2}$ spheres contain about 58 at $\% \mathrm{Cu}, 21$ at $\% \mathrm{Zr}$ and 21 at $\% \mathrm{Ag}$, which corresponds to the m-phase $\left(\mathrm{AgCu}_{4} \mathrm{Zr}\right)$.

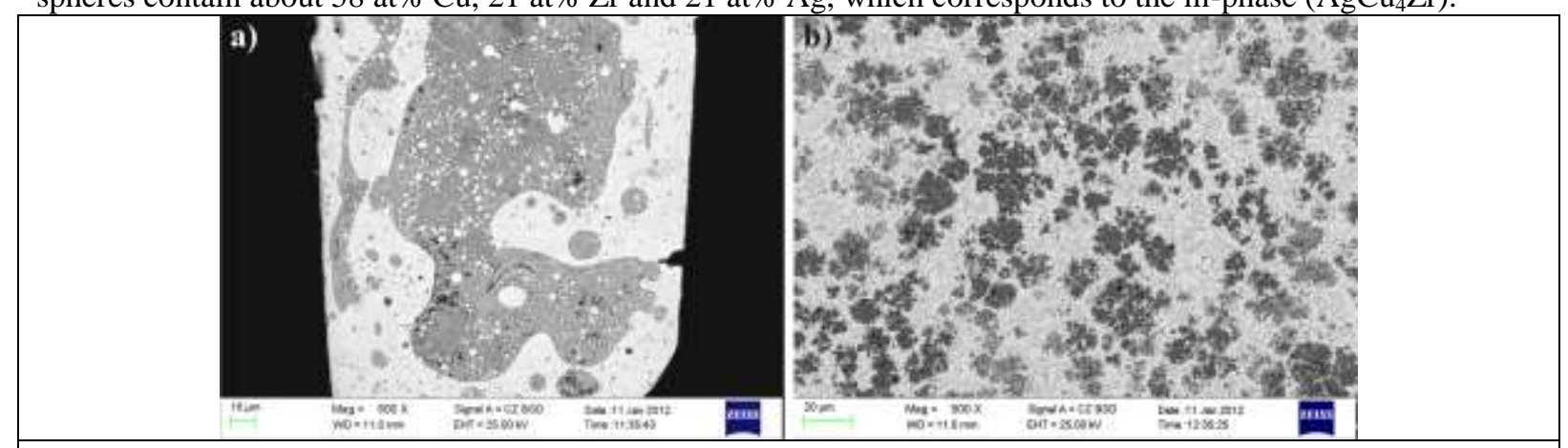

Fig.7: SEM micrographs of the $\mathrm{Cu}_{30} \mathrm{Zr}_{10} \mathrm{Ag}_{60}$ sample obtained in backscattered electrons:

a) taken at the tip b) $20 \mathrm{~mm}$ away from the tip

\section{Summary}

The microstructure and thermal properties of $\mathrm{Cu}-\mathrm{Zr}$-Ag alloys were investigated, which yielded the following results:

1. The present study confirms that a stable and metastable liquid state phase separation occur when $\mathrm{Zr}$ is added to the $\mathrm{Cu}-\mathrm{Ag}$ binary system. This ternary liquid decomposes into one $\mathrm{Ag}$-rich liquid $\left(\mathrm{L}_{1}\right)$ and another liquid rich in $\mathrm{Cu}$ and $\mathrm{Zr}\left(\mathrm{L}_{2}\right)$. 
2. Alloys have been solidified in a wedge-shaped $\mathrm{Cu}$ mould to analyze the influence of the cooling rate varied from $2000 \mathrm{~K} / \mathrm{s}$ to $20000 \mathrm{~K} / \mathrm{s}$. The volume fraction of the separated phases was determined by measuring the respective area fraction in master alloys and wedge-shaped samples. The results confirm that the volume fraction of the separated phases has increased due to higher cooling rate.

3. The boundaries of the liquid ternary miscibility gap have been enlarged owing to high cooling rate. The presence of different types of structures is observed in the samples, namely typical droplet-like, interconnected and irregular structures. The analysis of the structures as function of $\mathrm{L}_{1}$ yielded three clearly distinguishable structure types.

4. The particle size distribution of Ag-rich droplets in different positions of the wedge has been measured and related to the cooling rate. The size of Ag-rich phase increases when the cooling rate decreases but the melt flow has influence on this process. The difference in size of Ag-rich droplets is reduced at the top of the wedge. The coagulation of the $\mathrm{Cu}-\mathrm{Zr}$-rich droplets $\left(\mathrm{L}_{2}\right)$ is more significant compared to that of the Ag-rich $\left(\mathrm{L}_{1}\right)$ droplets. Along the major axis of the sample the volume of $\mathrm{Cu}-\mathrm{Zr}$-rich phase is not uniform. At the top of the wedge the volume fraction of the $\mathrm{L}_{2}$ liquid is smaller than at the tip because the undercooling is low.

5. Alloys with different compositions taken from the tip of the wedge have been studied by DSC. A small amount of amorphous phase was detected by DSC in an alloy with Ag contents above 39 at\%. The presence of amorphous phase was confirmed by TEM measurements.

\section{Acknowledgement}

The described work has been carried out as part of the TÁMOP-4.2.1.B-10/2/KONV-2010-0001 project within the framework of the New Hungarian Development Plan. The realization of this project is supported by the European Union, co-financed by the European Social Fund.

\section{References}

[1] ] S.A. Munitz, R. Abbaschian, Microstructure of Cu-Co alloys solidified at various supercoolings, Met. Mater. Transactions A 27A (1996) 4049-4059.

[2] W. Yang, H.Yua, J.H. Wang, C.C. Cai, Z.F. Xu, S. Li, F. Liu, G.C. Yang, Application of dendrite fragmentation to fabricate the homogeneous dispersed structure in undercooled Cu-Co immiscible alloy, J. Alloys Compd. 509 (2011) $9675-9678$

[3] X. Wei, J. Wang, Z. Yang, Z. Sun, D. Yu, X. Song, Liquid phase separation of Cu-Cr alloys during the vacuum breakdown, J. Alloys Compd. 509 (2011) 7116-7120

[4] N. Mattern, Structure formation in liquid and amorphous metallic alloys, J. Non-Crystalline Solids 353 (2007) 1723-1731

[5] J.H. Han, N. Mattern, D.H. Kim, J. Eckert, Microstructure and magnetic properties of GdeHfeCoeAl phase separated metallic glasses, J. Alloys Compd. 509S (2011) S42-S45.

[6] A.Inoue, Stabilization of metallic supercooled liquid and bulk amorphous alloys, Acta mater. 48 (2000) 279-30.

[7] M.J. He, H. Li, B. Yang, J. Zhao, H. Zhang, Z. Hu, Liquid phase separation and microstructure characterization in a designed Al-based amorphous matrix composite with spherical crystalline particle, J. Alloys Compd. 489 (2010) 535-540

[8] S. González D.V. Louzguine-Luzgina, J.H. Perepezko, A. Inoue, Large plasticity of a Mg42Li23Cu25Y10 multiphase composite, Mat. Sci. Eng. A 528 (2011) 5576-5584

[9] .A. Kündig, M. Ohnuma, T. Ohkubo, T. Abe, K. Hono, Glass formation and phase separation in the Ag-Cu-Zr system, Scripta Mater. 55 (2006) 449-452.

[10] D.H. Kang, I.H. Jung, Critical thermodynamic evaluation and optimization of the $\mathrm{Ag}-\mathrm{Zr}, \mathrm{Cu}-\mathrm{Zr}$ and $\mathrm{Ag}-\mathrm{Cu}-\mathrm{Zr}$ systems and its applications to amorphous $\mathrm{Cu}-\mathrm{Zr}-\mathrm{Ag}$ alloys, Intermetallics 18 (2010) 815-833.

[11] A. Castellero, D.H. Kang, I.H. Jung, G. Angella, M. Vedani, M. Baricco, Rapid solidification of silver-rich Ag-Cu-Zr alloys, J. Alloys Compd. 536S (2012) S148-S153.

[12] D. Janovszky, K. Tomolya, A. Sycheva, G. Kaptay, Stable miscibility gap in liquid Cu-Zr-Ag ternary alloy J. Alloys Compd. 541 (2012) 353-358

[13] K. Tomolya, D. Janovszky, M. Sveda, N. Hegman, A. Roosz, Analysis of Cu-Zr-Al amorphisable alloys produced by centrifugal Casting, Mat. Sci. Forum 649 (2010) 93-99

[14] J.H. Han, N. Mattern, D.H. Kim, J. Eckert, Microstructure and magnetic properties of Gd-Hf-Co-Al phase separated metallic glasses, J. Alloys Compd. 509S (2011) S42-S45. 